Check for updates

Cite this: RSC Adv., 2017, 7, 52366

Received 24th August 2017

Accepted 5th November 2017

DOI: 10.1039/c7ra09372a

rsc.li/rsc-advances

\section{Integrated electrocoagulation and membrane filtration for PAH removal from realistic industrial wastewater: effectiveness and mechanisms $\dagger$}

\begin{abstract}
Chenhao Gong, (DD ab Haiou Huang, ${ }^{\text {a }}$ Yu Qian, ${ }^{\mathrm{b}}$ Zhongguo Zhang ${ }^{\star \mathrm{b}}$ and Hongbin $\mathrm{Wu}^{\mathrm{c}}$
In this study, biologically treated, paper-making wastewater (PMWW) containing toxic polycyclic aromatic hydrocarbons (PAHs) was employed as the feedwater to investigate the effectiveness and mechanisms of integrated electrocoagulation (EC) and membrane filtration for the control of PAH pollution incurred by industrial wastewater discharge. The results showed that the integrated treatment was capable of removing more than $90 \%$ of polyaromatic hydrocarbon compounds (PAHs) and total organic carbon (TOC) from the wastewater. Specifically, the EC pretreatment contributed to approximately 40\% TOC removal and $75 \%$ PAH removal via the combined effects of coagulation and oxidation, thereby significantly lowering the contaminant loading of the LPRO treatment. Among the PAHs removed by the EC, 3-ring and 4-ring compounds, including acenaphthene, anthracene, phenanthrene, fluorene and fluoranthene were effectively removed. However, EC-induced degradation of humic-like and fulvic-like substances produced 2-ring PAH compounds, including naphthalene and dimethylnaphthalene, that did not exist in the PMWW. Very importantly, the LPRO treatment efficiently rejected residual PAH compounds in the EC effluent, including those formed by EC treatment, through the solution-diffusion process. Overall, the quality of the final effluent meets the requirements for industrial water reuse; this exhibits the potential value of EC-LPRO for PAH pollution control.
\end{abstract}

\section{Introduction}

Currently, one of the major environmental concerns at the global scale is the discharge of harmful pollutants from different industrial effluents and their accumulation in the aquatic environment. ${ }^{1}$ Among them, paper-making wastewater (PMWW) contains high levels of organic pollutants, including toxic polycyclic aromatic hydrocarbons (PAHs), even after biological treatment. ${ }^{2}$ As a result, discharge of PMWW without appropriate treatment causes slime growth, thermal impact, scum formation and color problems that kill fish in the receiving water body. More importantly, the accumulation of these toxic compounds may adversely affect human health and the soundness of the ecosystem. ${ }^{3}$ Therefore, PMWW treatment is of importance to sustainable wastewater management practices worldwide, and thus, cost-effective treatment technologies

${ }^{a}$ School of Environment, Beijing Normal University, No. 19 Xinjiekouwai Street, Beijing 100875, China. E-mail: huanghaiou@bnu.edu.cn; Fax: +86-10-58807734; Tel: +86-1058807734

${ }^{b}$ Environmental Protection Research Institute of Light Industry, Beijing Academy of Science and Technology, No. 1 Gao Li Zhang Road, Beijing 100095, China. E-mail: cn.zhang@163.com; Fax: +86-10-68456027; Tel: +86-10-68456047

'Wenzhou Administration of Shanxi Hydro-Complex, No. 198 Xiushan Road, Wenzhou 325000, China

† Electronic supplementary information (ESI) available. See DOI: 10.1039/c7ra09372a are in urgent need in order to control water pollution caused by PMWW. ${ }^{4}$

In the past decade, pressure-driven membrane filtration, in particular, reverse osmosis (RO) has gained increasing acceptance for water treatment and reuse applications. ${ }^{5-7}$ Traditional RO filtration has been found effective in removing most organic and inorganic pollutants, e.g., pesticides, disinfection byproducts, pharmaceutical, and heavy metals from aqueous solutions, but at relatively high applied filtration pressures. ${ }^{8,9}$ Recently, low-pressure reverse osmosis (LPRO) membranes were developed by various manufacturers to offer potential energy and cost savings in water treatment without noticeable compromise in permeate quality. ${ }^{10}$

Relatively high concentrations of organic pollutants in PMWW necessitate adoption of suitable pretreatment to reduce organic loading to the membrane. Among existing pretreatment technologies, electrocoagulation (EC) treatment has been increasingly applied to enhance organic pollutant removal during industrial wastewater treatment., ${ }^{3,11}$ During the EC treatment, iron or aluminum in the sacrificial anode is oxidized into divalent or trivalent metal ions and react with water to form metal hydroxide species, such as $\mathrm{Al}(\mathrm{OH})_{3}, \mathrm{Fe}(\mathrm{OH})_{2}$ and $\mathrm{Fe}(\mathrm{OH})_{3}$. These metal hydroxide species are capable of removing aqueous pollutants either by forming settleable complexes or coprecipitates. In addition, the oxidation reactions at the anode and the reduction reactions at the cathode may remove some 
pollutants by transformation. Moreover, hydrogen and oxygen air bubbles produced at the cathode and the anode, respectively, may remove flocs from water by flotation or strip volatile organic pollutants into the air.

Due to the aforementioned mechanisms, EC has been shown to effectively remove various organic compounds, ${ }^{12,13}$ as well as heavy metals, ${ }^{14,15}$ anions, ${ }^{16,17}$ microorganisms, ${ }^{18}$ and particulate matter from municipal wastewater, drinking water, and industrial wastewaters. ${ }^{19}$ Also, EC has been found to effectively remove organic matters from PMWW, ${ }^{3,11}$ but the removals of toxic organics, such as PAHs by EC have not been reported in the literature.

The integration of EC pretreatment with membrane filtration is an emerging technique for advanced wastewater treatment. ${ }^{20-22}$ Zhao et al. obtained high removals of hardness, chemical oxygen demand (COD) and turbidity by adjusting the current density, reaction time, $\mathrm{pH}$ and other treatment conditions of an integrated EC-RO treatment during produced water treatment. ${ }^{20}$ Pires da Silva et al. reported that EC pretreatment of oil emulsions followed by RO not only produced high-quality effluents that were suitable for reuse, but also significantly minimized membrane fouling. ${ }^{22}$ These findings suggest that EC treatment is potentially a suitable pretreatment for RO filtration used in the wastewater treatment, but relevant studies have not been reported in the literature.

Therefore, the specific objectives of this research were twofold: (1) assessing various types of membranes to be integrated with EC for efficient removal of PAHs in the industrial wastewater; and (2) investigating the mechanisms responsible for the removals of PAHs during the integrated EC-LPRO treatment. The outcome of this study provided valuable insights into the development of suitable technologies for the treatment of toxic organics, including PAHs in PMWW. A mechanistic understanding in advanced treatment of PMWW also offered instructive guidance for the treatment and reuse of other industrial wastewaters contaminated by toxic organic compounds.

\section{Materials and methods}

\subsection{Biologically treated paper-making wastewater}

PMWW used in this study was a biologically treated wastewater effluent collected from the secondary sedimentation tank of a wastewater treatment facility for a pulp and paper factory located in northern China. Water samples received in the lab were immediately prefiltered by using $1.2 \mu \mathrm{m}$ glass-fiber filters (Whatman GF/C) to remove small particles and then stored in the dark at $4{ }^{\circ} \mathrm{C}$ in a refrigerator. The main characteristics of the prefiltered wastewater sample are presented in Table S1 (ESI $\dagger$ ).

\subsection{Membranes}

A suitable membrane for integration with EC pretreatment was selected based upon their water permeability and organic removal efficiency. Therefore, a total of six different types of commercially available, flat-sheet membranes, including three ultrafiltration (UF) membranes, one nanofiltration (NF) membrane, one LPRO membranes, and one RO membrane, were tested in this study. The properties of these membranes are given in Table 1. Before use, each membrane was soaked in ultrapure water overnight, and then installed in a membrane filtration cell (Amicon 8200, USA) possessing a liquid volume of $200 \mathrm{~mL}$ and an effective membrane surface area of $28.7 \mathrm{~cm}^{2}$. Then after, at least $1 \mathrm{~L}$ of ultrapure water was filtered through the membrane at a constant pressure of $400 \mathrm{kPa}$ for $\mathrm{RO}$ and $\mathrm{NF}$ or $300 \mathrm{kPa}$ for UF to remove organic preservatives on the membrane.

\subsection{Electrocoagulation setup and protocol}

The bench-scale electrocoagulation reactor consisted of three iron electrodes, an EC reactor, and a direct current power supply (Fig. S1, ESI $\dagger$ ). The iron electrodes used in this study were $10 \mathrm{~cm}$ long, $4 \mathrm{~cm}$ wide, and $2 \mathrm{~mm}$ thick. The anode and the cathode were wired to the side electrodes, separately. The separation distance between each electrode was maintained at $1 \mathrm{~cm}$.

During each EC experiment, $1 \mathrm{~L}$ of the prefiltered wastewater was transferred into the EC reactor. Then, the reactor was operated at current densities of 20,30 , or $40 \mathrm{~mA} \mathrm{~cm}{ }^{-2}$. During each treatment run, the current density was maintained at a fixed value, while the voltages changed between 9 and 10 volts along with the increase of treatment time. The treated effluent was sampled from the reactor at regular time intervals during the treatment. The sampled water was kept in quiescent condition for 30 min to allow gravity settling of the coagulation sludge. Subsequently, the supernatant from each sample bottle was passed through a flat-sheet acetate fiber membrane with a nominal pore size of $0.22 \mu \mathrm{m}$ (Navigator/13-0.22) to separate the unsettled sludge from the treated water. All the EC

Table 1 Major properties of the membranes used in this study

\begin{tabular}{lllcl}
\hline Designation & Material $^{a}$ & Molecular weight cutoff $^{a}(\mathrm{Da})$ & Zeta potential $^{b}(\mathrm{mV})$ & Pure water permeability $^{c}\left(\mathrm{~L} \mathrm{~h}^{-1} \mathrm{~m}^{-2} \mathrm{bar}^{-1}\right)$ \\
\hline UF-PLAC & RC & 1000 & -11.5 & 5.0 \\
UF-PLBC & RC & 3000 & -9.3 & 7.2 \\
UF-PLCC & RC & 5000 & -14.4 & 9.4 \\
NF90 & PTFC & 200 & -60.5 & 9.7 \\
AK400 & PTFC & 95 & -50.9 & 6.8 \\
BW30 & PTFC & 110 & -61.2 & 4.4
\end{tabular}

${ }^{a}$ Reported by the manufacturers $(\mathrm{RC}=$ regenerated cellulose, $\mathrm{PTFC}=$ polyamide thin-film composite $) .{ }^{b}$ Measured in this study. ${ }^{c}$ Measured in this study. 
treatment experiments were conducted three times to ensure the reproducibility of the results.

\subsection{Membranes filtration protocol}

At the onset of each LPRO experiment, $150 \mathrm{~mL}$ of EC-treated water sample was fed into the filtration cell and continuously stirred by a magnetic stirrer at a constant speed of $400 \mathrm{rpm}$. The applied pressure for membrane filtration was maintained constantly at $400 \mathrm{kPa}$ for RO and NF or $300 \mathrm{kPa}$ for UF, by adjusting the pressure regulator of a nitrogen gas bottle connected to the filtration cell. The permeate sample was grabbed in a container and weighted with a digital balance (DEANTE, D\&T600). The cumulative permeate weight as a function of filtration time was automatically recorded on a PC via a data acquisition system. All membrane filtration experiments were conducted at a controlled room temperature of $25{ }^{\circ} \mathrm{C}$. All membrane filtration experiments were conducted three times to ensure reproducibility.

\subsection{Analytical methods}

2.5.1 PAH compounds. The raw and treated wastewater samples were analyzed for 16 types of PAH compounds regulated by United States Environmental Protection Agency. Due to the low initial concentrations, PAH compounds in the wastewater samples were concentrated by using solid-phase extraction (SPE) columns (Waters HLB) prior to GC/MS analysis. For each sample, the SPE column was pre-rinsed by $5 \mathrm{~mL}$ dichoromethane, activated by $5 \mathrm{~mL}$ methanol, and then rinsed by $5 \mathrm{~mL}$ pure water. Further, $500 \mathrm{~mL}$ of wastewater sample were filtered through the pre-cleaned column driven by a vacuum pump. Afterwards, the column was dried by nitrogen gas and eluted by $10 \mathrm{~mL}$ of dichloromethane. The eluent from the SPE column was collected and analyzed by using a gas chromatography system coupled with a mass spectrometry (GC/MS) detector (Agilent, 7890GC/5977A MS). The detailed analytical procedure was presented following: the capillary column for separation was an Agilent DB-5MS column $(30 \mathrm{~cm}$ $\times 250 \mu \mathrm{m} \times 0.25 \mu \mathrm{m}$ ). The samples were injected at a constant rate of $1 \mu \mathrm{L} \mathrm{min}{ }^{-1}$ and helium was used as the carrier gas at

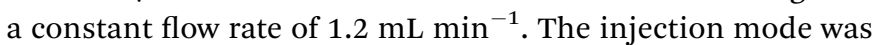
split sampling at a split ratio of $10: 1$ and an injection port temperature was $290{ }^{\circ} \mathrm{C}$. The oven program was started at $40{ }^{\circ} \mathrm{C}$ and held for $4 \mathrm{~min}$, increased at a rate of $10^{\circ} \mathrm{C} \mathrm{min}^{-1}$ to $160^{\circ} \mathrm{C}$ and held for $1 \mathrm{~min}$, increased at rate of $10^{\circ} \mathrm{C} \mathrm{min}{ }^{-1}$ up to $280^{\circ} \mathrm{C}$ and held for $4 \mathrm{~min}$, and finally increased at rate of $10^{\circ} \mathrm{C} \mathrm{min}^{-1}$ to $300^{\circ} \mathrm{C}$ and held for $10 \mathrm{~min}$. Solvent delay time was $8.0 \mathrm{~min}$, and the ion source (EI, $70 \mathrm{eV}$ ) for mass detection was kept at $275^{\circ} \mathrm{C}$.

The PAHs quantity method used in this work was based on the China standard for determination of 16 PAHs in water by GC-MS (GB/T 26411-2010). The concentrations of PAHs were quantified based upon their individual peak areas determined in the ion-scan mode in reference to standard solutions with known PAH concentrations. The standards for 16 PAH compounds, including dichloronaphthalene, dimethylnaphthalene, and the surrogate standards for a mixture (acenaphthene-d10, chrysene-d12, naphthaline-d8, pyrened12, phenanthrene-d10) and tetrachloro- $m$-xylene were purchased from AccuStandard company. The concentration of individual PAH compound was calculated by using the following three equations:

$$
\frac{A_{\mathrm{s}}}{A_{\mathrm{i}}}=K_{\mathrm{si}} \frac{M_{\mathrm{s}}}{M_{\mathrm{i}}}
$$

where $A_{\mathrm{S}}$ is the peak area of targeted PAH compound in the standard sample, $A_{\mathrm{i}}$ is the peak area of the internal standard, $M_{\mathrm{s}}$ is the mass of targeted PAH in the standard sample, $M_{\mathrm{i}}$ is the mass of the internal standard, $K_{\mathrm{si}}$ is the ratio of corresponding factors of the target compound to the internal standard.

$$
\frac{A_{\mathrm{t}}}{A_{\mathrm{i}}}=K_{\mathrm{ti}} \frac{M_{\mathrm{t}}}{M_{\mathrm{i}}}
$$

where $A_{\mathrm{t}}$ is the peak area of PAH surrogate in standard sample, $M_{\mathrm{t}}$ is the mass of PAHs surrogate, $K_{\mathrm{ti}}$ is the ratio of corresponding factors of PAHs surrogate to internal standard compounds.

$$
\frac{A_{s}}{A_{\mathrm{t}}}=K_{\mathrm{st}} \frac{M_{\mathrm{s}}}{M_{\mathrm{t}}}
$$

where $K_{\mathrm{st}}$ is the ratio of corresponding factors of target PAHs to PAHs surrogate.

2.5.2 TOC fractionation. The total organic carbon (TOC) concentrations of water samples were measured by using a combustion-type organic carbon analyzer (Elementar, Liqui TOC II). Size exclusion chromatography with organic carbon and UV detection (SEC-OCD/UV) was applied to determine the size fractionation of organic matter in water samples. The SEC system comprised a high-pressure liquid chromatography system (Wufeng, LC-100, China) equipped with a TSK-GEL $\mathrm{G}^{2} 000 \mathrm{PW}_{\mathrm{XL}}$ column (Tosoh Bioscience, Japan). A phosphate buffer solution consisting of $1.2 \mathrm{~g} \mathrm{~L}^{-1} \mathrm{NaH}_{2} \mathrm{HPO}_{4}$ and $2.5 \mathrm{gL}^{-1}$ $\mathrm{KH}_{2} \mathrm{PO}_{4}$ was employed as the mobile phase, and the flow rate was controlled at $0.5 \mathrm{~mL} \mathrm{~min}^{-1}$. Prior to each measurement, the water sample was prefiltered through the acetate fiber membrane (Navigator/13-0.22) and injected into the SEC column at a fixed volume of $50 \mu \mathrm{L}$.

2.5.3 EEM analysis. Excitation emission matrix (EEM) spectroscopic analysis of water samples was performed using a Hitachi F-4600 fluorescence spectrophotometer to determine the composition of organic fluorophores in the PMWW. Excitation and emission slit widths were set to $5 \mathrm{~nm}$, the excitation spectrum was scanned from 200 to $500 \mathrm{~nm}$ and the corresponding emission spectrum was recorded from 220 to $600 \mathrm{~nm}$. Fluorescence EEM quantification was performed by calculating the overall reduction of fluorophores obtained by summing the individual peak intensities. ${ }^{23}$

2.5.4 Membrane characterization. Zeta potentials of the studied membranes were measured in $0.83 \mathrm{mmol} \mathrm{L}^{-1} \mathrm{KCl}$ solution by using a SurPASS electrokinetic analyzer (Anton Paar $\mathrm{GmbH}$, Austria). The pure water permeability of the membranes was measured in membrane filtration cell with ultrapure water (Amicon 8200, USA). 


\section{Results and discussion}

\subsection{Performance optimization for the EC-LPRO process}

3.1.1 Determination of EC conditions. The operational conditions for EC pretreatment, including current density and pretreatment time were investigated in this study in order to maximize the contaminant removal performance and minimize the energy consumption of the downstream membrane filtration process. For the convenience of sample analyses, TOC was employed herein as a surrogate parameter for PAHs removal.

For the purpose of TOC removal, the current density was varied during the EC treatment from $20 \mathrm{~mA} \mathrm{~cm}^{-2}$ to $40 \mathrm{~mA} \mathrm{~cm}{ }^{-2}$, resulting in decreases in the residual TOC concentrations with the treatment time (Fig. S2, ESI $\dagger$ ), and accordingly, increases in TOC removals. However, the decreases in TOC concentrations were minor when the current density increased from $30 \mathrm{~mA} \mathrm{~cm}{ }^{-2}$ to $40 \mathrm{~mA} \mathrm{~cm}^{-2}$ (Fig. S2, ESI $\dagger$ ). In addition, the results under $30 \mathrm{~min}$ was better on the removal of specific type of pollutants in the following analysis; based on this, the current density was thus set at $30 \mathrm{~mA} \mathrm{~cm}{ }^{-2}$ for EC pretreatment. Under this condition, the removal efficiency quickly reached $28.0 \%$ in $5 \mathrm{~min}$ and then slowly increased to $42.5 \%$ in the end of $30 \mathrm{~min}$ treatment.

3.1.2 Determination of a suitable membrane. The structural properties of membranes are known to affect their selectivity to organic solutes in the feed water, as well as their permeability to water. The two effects were indeed witnessed in this study. As shown in Fig. 1, the three UF membranes only removed $14.7-20.6 \%$ of TOC and the lowest removal was observed with the 5000 Da MWCO membrane. In comparison, the NF membrane with a MWCO value of 200 Da removed $72 \%$ of TOC. Greater TOC removal efficiencies were obtained with the RO membrane and the LPRO membrane. The LPRO membrane with a MWCO value of 95 Da removed 96\%, while the RO membrane with a MWCO value of 110 Da removed $92 \%$

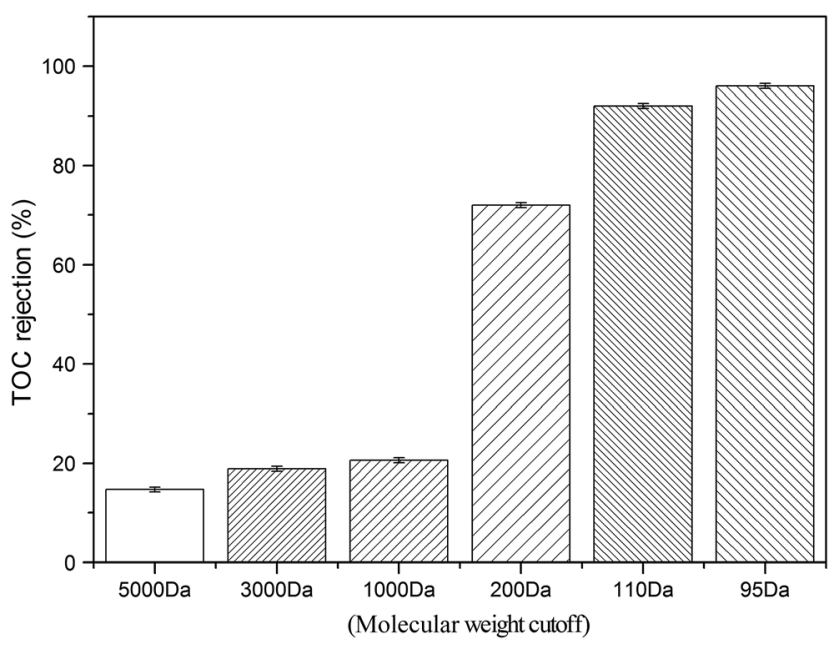

Fig. 1 TOC rejection observed with different membranes. Filtration conditions: initial $\mathrm{pH}=7.85$, cell stirring speed $=400 \mathrm{rpm}$, temperature $=25^{\circ} \mathrm{C}$, trans-membrane pressure $=300 \mathrm{kPa}$ for UF, and $400 \mathrm{kPa}$ for other membranes. Error bars represent standard deviations obtained in triplicate runs.

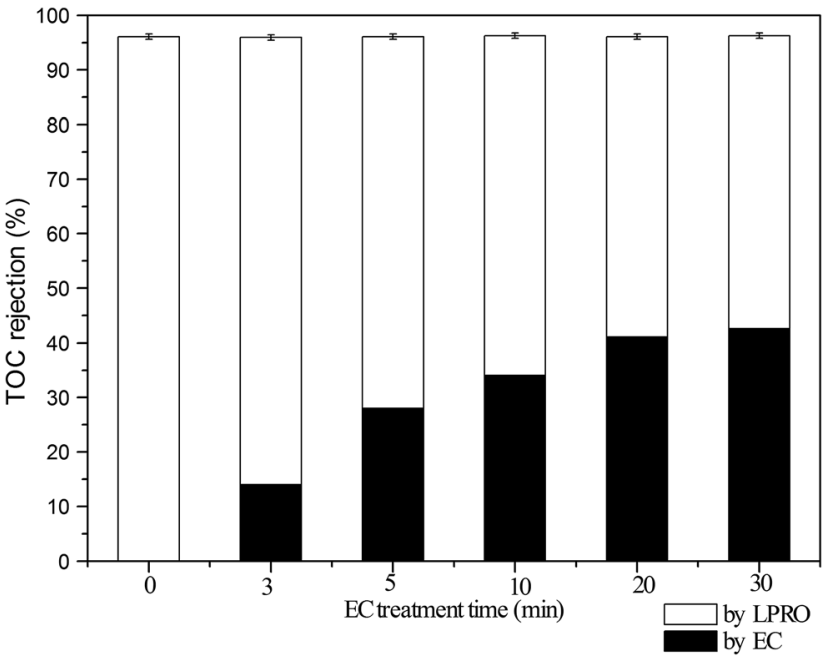

Fig. 2 Effect of $\mathrm{EC}$ treatment time on $\mathrm{TOC}$ rejection by $\mathrm{EC}$ and downstream LPRO process. EC treatment conditions: initial $\mathrm{pH}=7.85$, current density $=30 \mathrm{~mA} \mathrm{~cm}{ }^{-2}$, temperature $=25^{\circ} \mathrm{C}$; LPRO conditions: trans-membrane pressure $=400 \mathrm{kPa}$, stirring speed $=400 \mathrm{rpm}$, temperature $=25^{\circ} \mathrm{C}$. Error bars represent standard deviations obtained in triplicate runs.

of total organics in the PMWW. Overall, the TOC removal efficiencies obtained in this study increased as the MWCO values of the membranes decreased.

On the other hand, the pure water permeability of the membranes varied significantly with the changes in MWCO values and the membrane type. As shown in Table 1, the permeability of UF membranes decreased from $9.4 \mathrm{~L} \mathrm{~h}^{-1} \mathrm{~m}^{-2} \mathrm{bar}^{-1}$ to $5.0 \mathrm{~L} \mathrm{~h}^{-1} \mathrm{~m}^{-2}$ bar $^{-1}$ as their MWCO values decreased from $5000 \mathrm{Da}$ to $1000 \mathrm{Da}$. In comparison, the pure water permeability of the NF and the RO membranes did not change in accordance with their MWCO values. Among them, the NF membrane

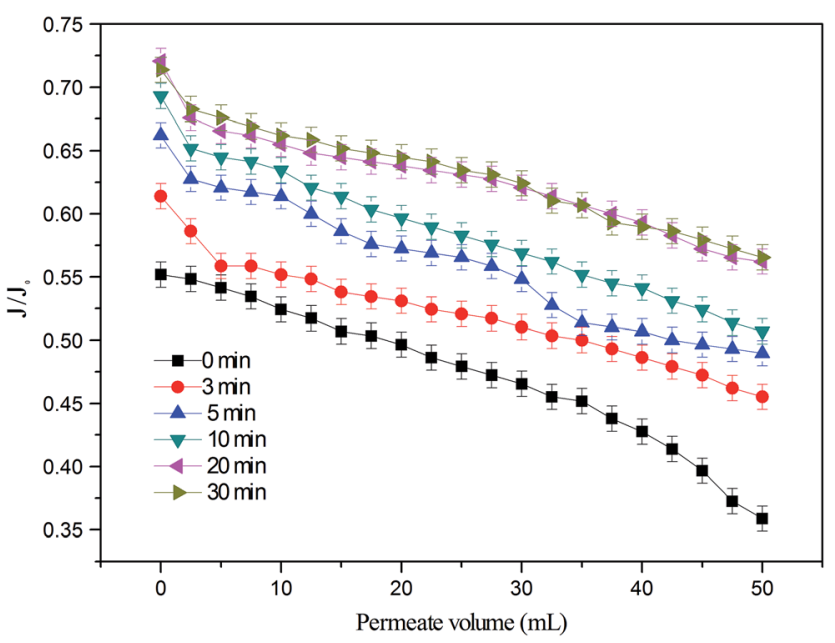

Fig. 3 Effect of EC treatment time on membrane fouling. EC treatment conditions: initial $\mathrm{pH}=7.85$, current density $=30 \mathrm{~mA} \mathrm{~cm}$, temperature $=25^{\circ} \mathrm{C}$; LPRO conditions: trans-membrane pressure $=$ $400 \mathrm{kPa}$, stirring speed $=400 \mathrm{rpm}$, temperature $=25^{\circ} \mathrm{C}$. Error bars represent standard deviations obtained in triplicate runs. 
Table 2 Characteristics of the PAH compounds detected in PMWW and produced during the EC treatment

\begin{tabular}{|c|c|c|c|c|c|}
\hline Name & Chemical structure $^{c}$ & Chemical formula & $\begin{array}{l}\text { Molecular weight } \\
\left(\mathrm{g} \mathrm{mol}^{-1}\right)\end{array}$ & $\log K_{\mathrm{ow}}$ & $\begin{array}{l}\text { Solubility in } \\
\text { water at } 25^{\circ} \mathrm{C}\left(\mathrm{mg} \mathrm{L}^{-1}\right)\end{array}$ \\
\hline Anthracene $^{a}$ & & $\mathrm{C}_{14} \mathrm{H}_{10}$ & 178.2 & 4.45 & 0.044 \\
\hline Fluoranthene ${ }^{a}$ & & $\mathrm{C}_{16} \mathrm{H}_{10}$ & 202.3 & 5.16 & 0.23 \\
\hline Fluorene ${ }^{a}$ & & $\mathrm{C}_{13} \mathrm{H}_{10}$ & 166.2 & 4.18 & 1.89 \\
\hline Phenanthrene $^{a}$ & & $\mathrm{C}_{14} \mathrm{H}_{10}$ & 178.2 & 4.46 & 1.15 \\
\hline Dimethylnaphthalene $e^{b}$ & & $\mathrm{C}_{12} \mathrm{H}_{12}$ & 156.2 & 4.31 & 11 \\
\hline
\end{tabular}

${ }^{a}$ PAH compounds detected in PMWW. ${ }^{b}$ PAH compounds detected after the EC treatment. ${ }^{c}$ For compound with multiple congeners, only one congener is shown.

possessed the highest permeability of $9.65 \mathrm{~L} \mathrm{~h}^{-1} \mathrm{~m}^{-2} \mathrm{bar}^{-1}$, next with the LPRO membrane, while the RO membrane has the lowest permeability albeit similar MWCO values. Considering the pure water permeability and TOC rejection, the LPRO membrane was selected in this study for the integration with EC pretreatment.

3.1.3 Performance of EC-LPRO. The EC-LPRO process exhibited similar removal efficiencies for TOC as compared to that obtained with the LPRO alone (Fig. 2). In this regard, the major function of EC pretreatment in the integrated treatment was the reduction of the organic loading to the LPRO. For example, EC pretreatment for 30 min reduced the TOC in the PMWW by approximately $45 \%$; this means that the TOC loading to the LPRO membrane was reduced by almost a half.

In addition to similar TOC removal, significant decreases in TOC concentrations shown above (Fig. 2) were coincident with noticeable mitigation in membrane fouling (Fig. 3). Without EC pretreatment, the normalized permeate flux $\left(J / J_{0}\right)$ for the LPRO declined to 0.35 after filtration of $50 \mathrm{~mL}$ of PMWW. In comparison, the final $J / J_{0}$ value increased with increasing EC treatment time and achieved 0.56 at a pretreatment time of $30 \mathrm{~min}$. Overall, the EC-LPRO process exhibited better water productivity than the standalone LPRO process when other treatment conditions were unchanged.

\subsection{PAH removal by the EC-LPRO process}

3.2.1 Characteristics of PAH compounds in PMWW. According to the GC/MS results, seven types of PAHs were detected in the PMWW at levels above the method detection limits. The characteristics of these compounds are listed in Table 2 and their concentrations are tabulated in Table 3. As shown in Table 2, five PAH compounds consist of three benzene rings, and the other two possess either two (dichloronaphthalene) or four aromatic rings (fluoranthene). The molecular weights of these PAH compounds range between 152.2 Da for acenaphthylene and 202.3 Da for fluoranthene and are greater than the molecular weight cut-off of the LPRO membrane (95 Da, see Table 1). Moreover, the solubility values of these compounds in water are in a low range of $0.044-4 \mathrm{mg} \mathrm{L}^{-1}$, indicating that they are poorly soluble in water. 
Table 3 Variations in PAH concentrations during the EC-LPRO treatment ${ }^{a}$

\begin{tabular}{|c|c|c|c|c|c|c|}
\hline \multirow[b]{2}{*}{ Compound } & \multicolumn{3}{|c|}{ Concentration $\left(\mathrm{ng} \mathrm{L}^{-1}\right)$} & \multicolumn{3}{|c|}{ Removal percentage (\%) } \\
\hline & Initial & After EC & After LPRO & $\mathrm{EC}$ & LPRO & $\begin{array}{l}\text { EC + } \\
\text { LPRO }\end{array}$ \\
\hline Acenaphthene & 425 & 80 & 40 & 81.2 & 50.0 & 90.6 \\
\hline Acenaphthylene & 16 & 15 & ND & 6.2 & 100 & 100 \\
\hline Anthracene & 321 & 201 & 18 & 37.4 & 91.0 & 94.4 \\
\hline Fluorene & 611 & 213 & 25 & 65.1 & 88.3 & 95.9 \\
\hline Phenanthrene & 589 & 249 & 35 & 57.7 & 85.9 & 94.1 \\
\hline Dimethylnaphthalene & ND & 1.0 & ND & - & 100 & 100 \\
\hline Naphthalene & ND & 1.8 & ND & - & 100 & 100 \\
\hline
\end{tabular}

The PAH compounds were present in PMWW at two distinctive concentration levels (Table 3). Four of them, acenaphthene, anthracene, fluoranthene, and fluorene, existed at relatively high concentrations, ranging from $321-611 \mathrm{ng} \mathrm{L}^{-1}$. Comparatively, the concentrations of acenaphthylene, dichloronaphthalene, and fluoranthene were in a low range of $16-80 \mathrm{ng} \mathrm{L}^{-1}$. As described below, PAH concentration appears to be an important factor relevant to the efficiencies of EC and LPRO in PAH removals.

3.2.2 Effects of EC pretreatment on PAH composition. EC pretreatment affected the concentrations and composition of PAHs in PMWW (Table 3). On a total mass basis, EC treatment removed $75 \%$ of PAHs in PMWW in $30 \mathrm{~min}$. Among the seven types of PAHs present in the PMWW, 3-ring PAH compounds, including acenaphthene, anthracene, phenanthrene, fluorine, and 4-ring compound (fluoranthene) were removed to different extents. Comparatively, the 2-ring PAH compound, dichloronaphthalene was only removed by $5.5 \%$. More importantly, two new 2-ring PAH compounds, i.e., naphthalene and dimethylnaphthalene were also produced. Therefore, 3- or 4-ring PAH compounds appeared to be more readily removed by EC than 2-ring compound. This finding is consistent with that obtained by Lin et al., ${ }^{24}$ since they also found the degradation efficiency of high molecular weight PAHs was even higher than that of light molecular weight PAHs.

More efficient removals of 3- and 4-ring compounds by the EC treatment are also coincident with their relatively high concentrations in PMWW. As shown in Table 3, the five types of PAH compounds removable by EC all existed at initial concentrations above $80 \mathrm{ng} \mathrm{L}^{-1}$, while the two poorly removed compounds were present at concentrations below $20 \mathrm{ng} \mathrm{L}^{-1}$. This suggests the potential effect of PAH concentration on its degradation/removal during EC treatment.

According to the literature, the degradation rates of PAHs by advanced oxidation treatment increase as the molecular weight and/or the number of aromatic rings increases. ${ }^{25}$ Future research is warranted to probe the relative importance of concentration and chemical properties of PAHs to their removals/degradation by EC treatment.

3.2.3 Effects of LPRO on PAH composition. Similar to TOC removal (Fig. 2), the downstream LPRO treatment removed most of the residual PAH compounds in the PMWW, including compounds being present in the PMWW (dichloronaphthalene, acenaphthylene, and fluoranthene), as well as those produced during EC treatment, i.e., naphthalene and dimethylnaphthalene (Table 3). Practically, the removals of naphthalene and dimethylnaphthalene by the LPRO prevented secondary contamination caused by the intermediates formed during EC treatment, which is plausible from the standpoints of industrial water reuse and PAH pollution control. However, acenaphthene, anthracene, phenanthrene, and fluorene, were still detected in the LPRO permeate, which indicates that RO is an efficient but not an absolute barrier for PAH under certain conditions (Table 3).

Passage of PAH compounds through the LPRO membrane appeared to be occur when those compounds existed at relatively high influent concentrations (above $c a .80 \mathrm{ng} \mathrm{L}^{-1}$ ). Incomplete removal of organics in industrial wastewater was also found by other researchers. For example, Ochando-Pulido et al. found that RO rejected most of the organics contained in olive mill wastewater, but there was still $1.9 \%$ of organic pollutants cannot be removed in filtration. ${ }^{26}$

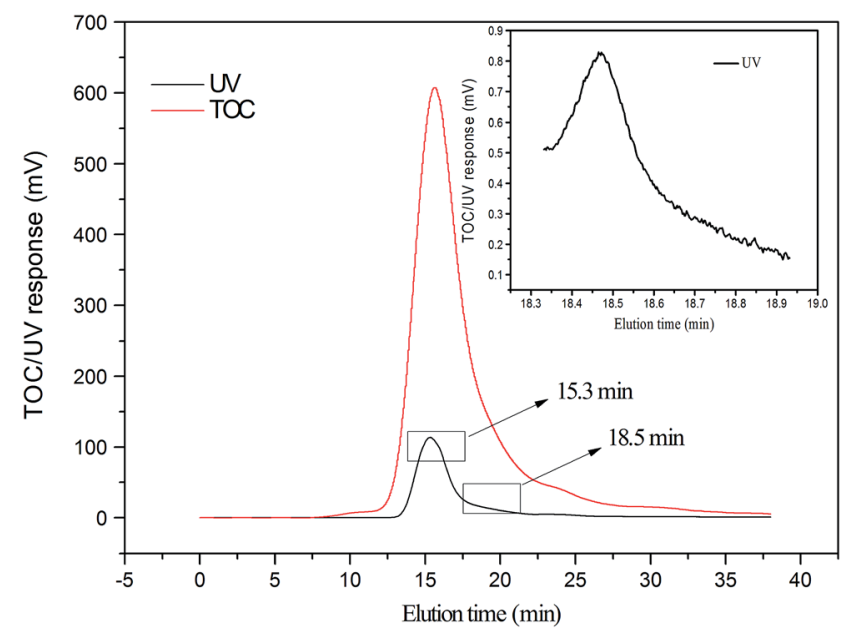

Fig. 4 Composition of organic pollutants in the PMWW determined by the SEC-OCD/UV. 


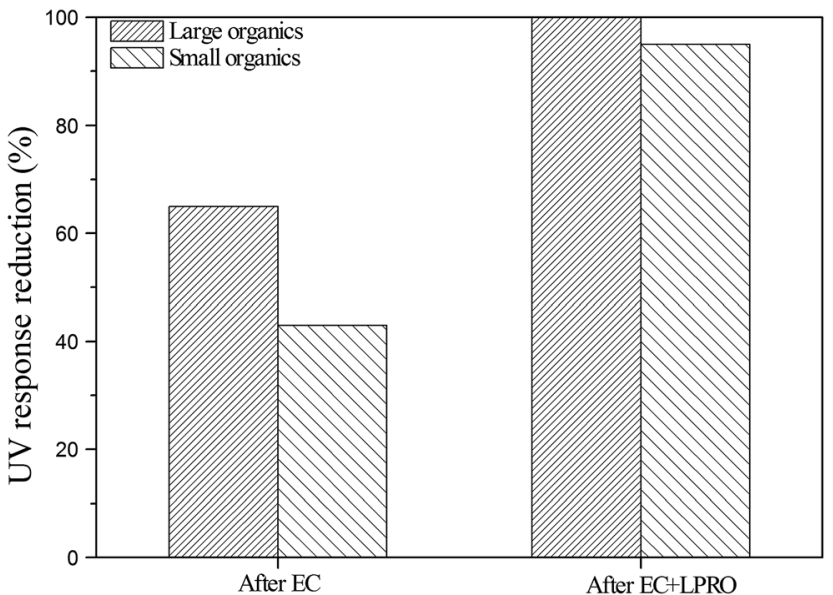

Fig. 5 Percentage reductions in the SEC-UV responses for large and small organic fractions after EC-LPRO treatment. EC treatment conditions: initial $\mathrm{pH}=7.85$, current density $=30 \mathrm{~mA} \mathrm{~cm}^{-2}$, treatment time $=30 \mathrm{~min}$, temperature $=25^{\circ} \mathrm{C}$; LPRO filtration conditions: transmembrane pressure $=400 \mathrm{kPa}$, stirring speed $=400 \mathrm{rpm}$, temperature $=25^{\circ} \mathrm{C}$.

\subsection{Mechanisms for organic pollutant removal during EC- LPRO}

3.3.1 SEC-OCD/UV analyses. In addition to lowconcentration PAH compounds, major constituents of organics in the PMWW were analyzed by both SEC-OCD/UV and EEM analyses. According to the SEC-OCD/UV results (Fig. 4), two major organic fractions were identified in the PMWW. The large peak observed at the elution time of $15.3 \mathrm{~min}$ and the small shoulder peak at 18.5 min correspond to two organic fractions having apparent molecular weights of approximately $800 \mathrm{~g} \mathrm{~mol}^{-1}$ (large organics) and $200 \mathrm{~g} \mathrm{~mol}^{-1}$ (small organics), respectively, in reference to the polyethylene glycol/polyethylene oxide standards. Both fractions exhibited UV-absorbing properties at an incident light wavelength of $254 \mathrm{~nm}$.

SEC/UV analyses of the step-wise treated effluents further revealed how organics were separately removed by EC and LPRO during the EC-LPRO treatment. After the EC pretreatment, the peak area for the large organics fraction was reduced by $65 \%$, while the peak area for the small organics fraction was reduced by $43 \%$ (Fig. 5), suggesting that the EC pretreatment was more efficient in removing large organics than small organics. After the LPRO treatment, the large-organic peak present in the ECpretreated effluent was completely removed, while the peak area for the small organics peak was reduced by $95 \%$. A small amount of small organics still passed through the membrane, possibly due to their relatively low molecular weight ( $c a .200$ Da). According to Table 2, all PAH compounds detected in PMWW or the treated effluent possess molecular weights close or below $200 \mathrm{Da}$ and belong to this SEC fraction. Therefore, the SEC results shown in Fig. 5 were generally in agreement with the PAH removal results (Table 3 ).

3.3.2 Fluorescence EEM analyses. Further EEM analysis also revealed dominance of aromatic substances in the PMWW. All together, five primary EEM peaks were identified (Fig. 6): (1) bicyclic aromatic and small hard compounds at Ex. 230-235 nm/Em. 340-360 nm (peak 1), which probably contained aromatic organics such as ethylbenzene, naphthalene, and xylene, ${ }^{27}$ (2) humic acid-like substances at Ex. 250-260 nm/Em. 420-440 nm (peak 2), ${ }^{28}$ (3) protein tryptophan-like substances at Ex. 275-285 nm/Em. 340-360 nm (peak 3), ${ }^{28}$ (4) humic acid-like substances with a small amount of fulvic acid-like substances at Ex. 275-300 nm/Em. 420-440 nm (peak 4), ${ }^{29}$ and (5) fulvic acidlike substances at Ex. $325-350 \mathrm{~nm} / \mathrm{Em} .420-440 \mathrm{~nm}$ (peak 5). ${ }^{27,30}$ Since aromatic compounds are known to be refractory to biodegradation, these results explained why the biological treatment adopted by the paper mill failed to remove these organics.
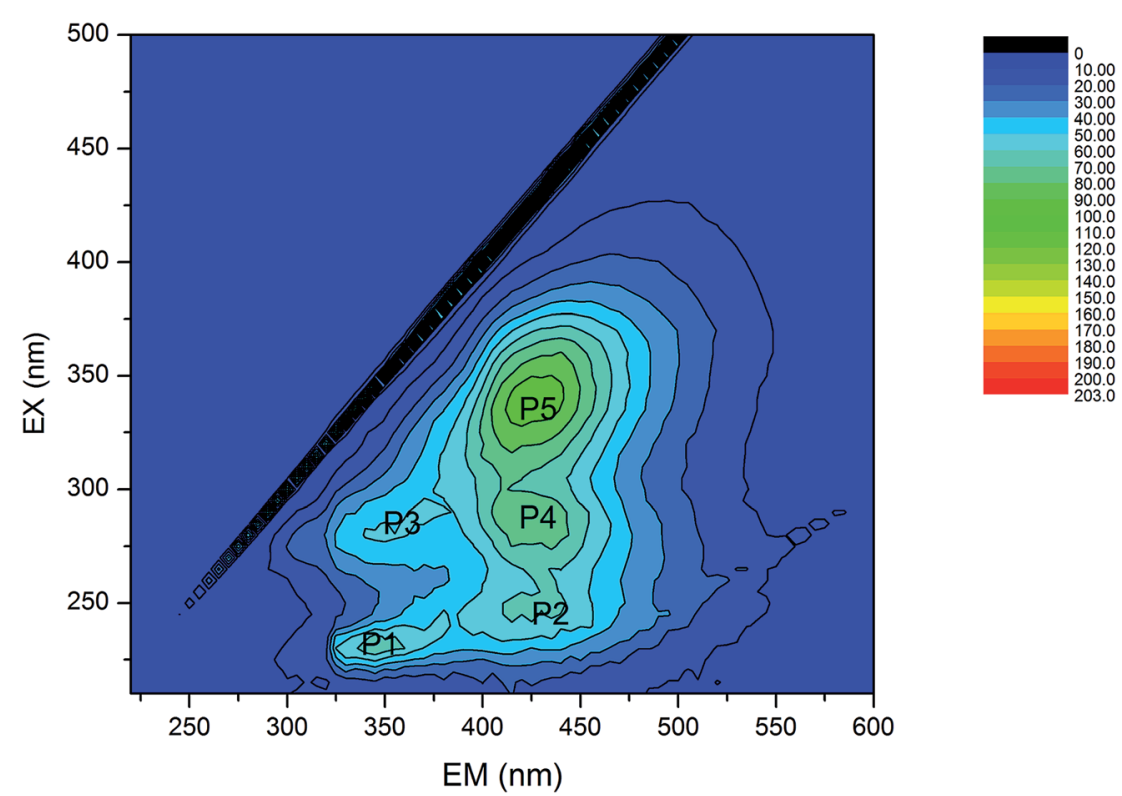

Fig. 6 Composition of organic pollutants in the PMWW determined by fluorescence excitation-emission matrix spectroscopy. 


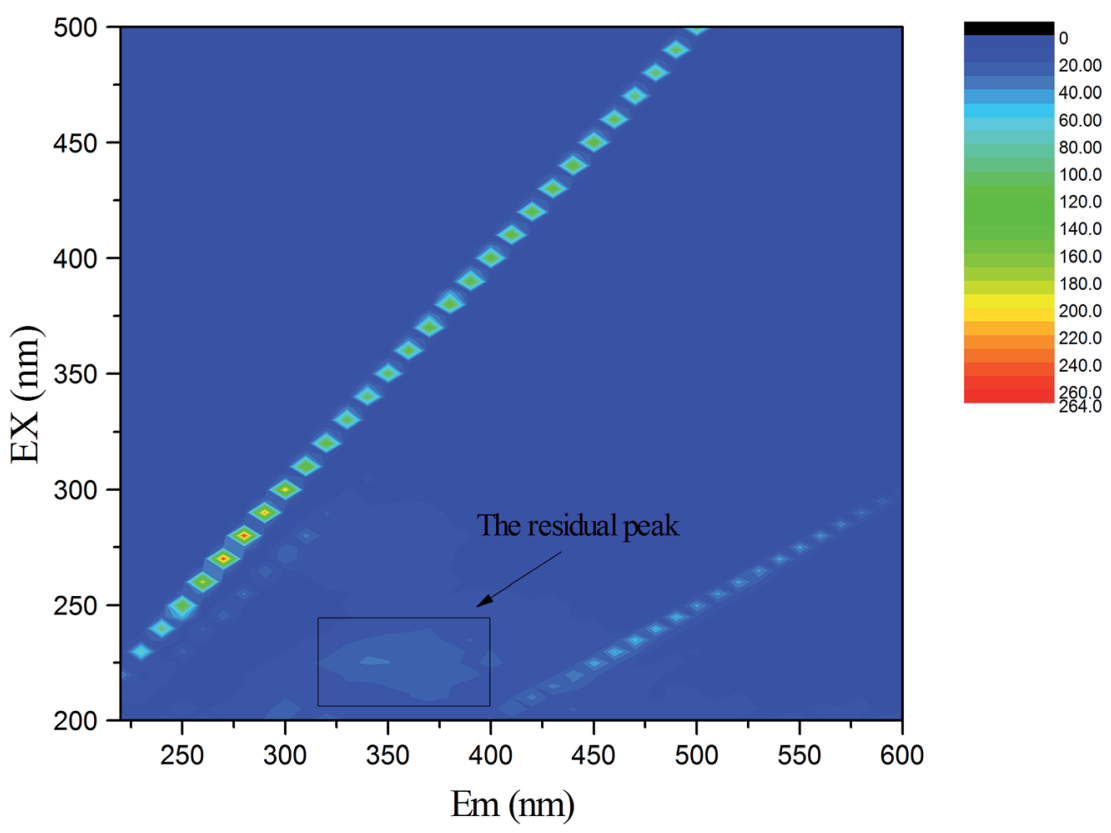

Fig. 7 Fluorescence excitation-emission matrix spectra of the wastewater treated by the EC-LPRO process. EC treatment conditions: initial $\mathrm{pH}=7.85$, current density $=30 \mathrm{~mA} \mathrm{~cm}{ }^{-2}$, treatment time $=30 \mathrm{~min}$, temperature $=25^{\circ} \mathrm{C}$; LPRO conditions: trans-membrane pressure $=$ $400 \mathrm{kPa}$, stirring speed $=400 \mathrm{rpm}$, temperature $=25^{\circ} \mathrm{C}$.

The EC pretreatment not only reduced the TOC level of the wastewater, but also changed its organic composition, (Fig. S3, ESI $\dagger$ ). The fluorescent intensities of different EEM fractions underwent significant changes after EC treatment and their removal efficiencies followed the order of peak $4>$ peak $2>$ peak 5. EC treatment efficiently removed humic acid-like and fulvic acid-like fluorescent compounds. Oppositely, the fluorescent intensities of bicyclic aromatic compounds (peak 1) and protein tryptophan-like substances (peak 3) increased by $300 \%$ and $150 \%$, respectively, suggesting the production of the two organic components during EC treatment. The downstream LPRO treatment removed residual organics in the EC-treated effluent, except for a small amount of bicyclic aromatic and small hard compounds (Fig. 7). These results were consistent with the finding that some PAHs passed through the LPRO membrane into the permeate (Table 3). The production of bicyclic aromatic compounds and protein-like substances during EC treatment also took place coincidently with the generation of dimethylnaphthalene and naphthalene.

EEM analyses revealed that the transformation of organic pollutants during the EC pretreatment of the integrated process. Specifically, the humic acid-like and fulvic acid-like fluorescent compounds were degraded during the electrochemical oxidation process and formed the final products included new PAH compounds (i.e., naphthalene and dimethylnaphthalene) and bicyclic aromatic compounds and protein tryptophan-like substances (Fig. S3, ESI†). Similarly, Ciputra et al. also found that the recalcitrant dissolved organic matter from paper mill effluent was easily degraded into bicyclic aromatic compounds and other small organic in the oxidation treatment. ${ }^{31}$

\section{Conclusions}

A biologically-treated, paper-making wastewater effluent containing PAHs was treated by electrocoagulation, followed by low-pressure reverse osmosis to explore the effectiveness and mechanisms of the integrated treatment for advanced industrial water treatment. The experimental results demonstrated that EC mitigated $40 \%$ of the organic loading and $75 \%$ of PAHs to the LPRO, and significantly reduced the fouling of downstream membranes. On the other hand, LPRO served as a reliable barrier for a majority of residual organics in the ECpretreated effluent, including harmful by-products formed by EC. Overall, the EC-LPRO treatment removed $96 \%$ of organic matter and $94 \%$ of PAHs in the PMWW. The high-quality, final effluent is expected to meet the requirements for industrial wastewater reuse purposes.

Mechanistically, EC treatment primarily removed medium molecular weight ( $\sim 800 \mathrm{Da})$ humic-like or fulvic-like organics, as well as 3-ring and 4-ring PAH compounds present in the PMWW, possibly because of their relatively high concentrations and reactivities during the coagulation and electrochemical processes. However, some 2-ring PAH compounds were produced due to incomplete electrochemical degradation of humic acid-like and fulvic acid-like substances. Furthermore, the LPRO treatment was effective in removing a majority of organics in PMWW or EC-pretreated effluent because of the small molecular weight cutoff of the membrane (95 Da). Only limited amounts of small organics, such as PAH compounds at influent concentrations of $80 \mathrm{ng} \mathrm{L}^{-1}$ or more, passed into the membrane permeate. 
Overall, the integrated EC-LPRO treatment was highly effective in removing PAHs contained in the PMWW; these findings provided important baseline information for potential large-scale application of EC-LPRO technique to advanced industrial wastewater treatment and reuse.

\section{Conflicts of interest}

There are no conflicts to declare.

\section{Acknowledgements}

The authors greatly appreciate the financial support of the Special Funds for Technological Development of Research Institutes from the Ministry of Science and Technology of China (2013EG111129), the Program for Youth Scientists of the Beijing Academy of Science and Technology (201505), and the Special Fund of the State Joint Key Laboratory for Environmental Simulation and Pollution Control (270403GK).

\section{References}

1 M. Boroski, A. C. Rodrigues, J. C. Garcia, A. P. Gerola, J. Nozaki and N. Hioka, J. Hazard. Mater., 2008, 160, 135-141. 2 S. Zodi, J. N. Louvet, C. Michon, O. Potier, M. N. Pons, F. Lapicque and J. P. Leclerc, Sep. Purif. Technol., 2011, 81, 62-68.

3 R. Katal and H. Pahlavanzadeh, Desalination, 2011, 265, 199205.

4 M. L. Hewitt, T. G. Kovacs, M. G. Dube, D. L. MacLatchy, P. H. Martel, M. E. McMaster, M. G. Paice, J. P. Parrott, M. R. Van Den Heuvel and G. J. Van Der Kraak, Environ. Toxicol. Chem., 2008, 27, 682-697.

5 J. Radjenovic, M. Petrovic, F. Venturac and D. Barcelo, Water Res., 2008, 42, 3601-3610.

6 C. Bellona and J. Drewes, J. Membr. Sci., 2005, 249, 227-234.

7 M. G. Buonomenna, RSC Adv., 2013, 3, 5694-5740.

8 S. R. Mozaz, M. Ricart, M. K. Schulmeyer, H. Guasch, C. Bonnineau, L. Proia, M. L. D. Alda, S. Sabater and D. Barcelo, J. Hazard. Mater., 2015, 282, 165-173.

9 J. Yoon, G. Amy, J. Chung, J. Sohn and Y. Yoon, Chemosphere, 2009, 77, 228-235.
10 A. Somrani, A. H. Hamzaous and M. Pontie, Desalination, 2013, 317, 184-192.

11 M. Ugurlu, A. Gurses, C. Dogar and M. Yalcin, J. Environ. Manage., 2008, 87, 420-428.

12 J. Q. Jiang, N. Graham, C. Andre, G. H. Kelsall and N. Brandon, Water Res., 2002, 36, 4064-4078.

13 P. Canizares, F. Martinez, C. Jimenez, J. Lobato and M. A. Rodrigo, Environ. Sci. Technol., 2006, 40, 6418-6424.

14 G. Mouedhen, M. Feki, M. D. P. Wery and H. F. Ayedi, J. Hazard. Mater., 2008, 150, 124-135.

15 G. C. C. Yang and C. M. Tsai, J. Membr. Sci., 2006, 286, 36-44. 16 N. Mameri, A. R. Yeddou, H. Lounici, D. Belhocine, H. Grib and B. Bariou, Water Res., 1998, 32, 1604-1612.

17 F. Shen, X. Chen, P. Gao and G. Chen, Chem. Eng. Sci., 2003, 58, 987-993.

18 B. Zhu, D. A. Clifford and S. Chellam, Water Res., 2005, 39, 3098-3108.

19 P. K. Holt, G. W. Barton, M. Wark and C. A. Mitchell, Colloids Surf., A, 2002, 211, 233-248.

20 S. Zhao, G. Huang, G. Cheng, Y. Wang and H. Fu, Desalination, 2014, 344, 454-462.

21 W. Den and C. Wang, Sep. Purif. Technol., 2008, 59, 318-325.

22 J. R. Pires da Silva, F. Mercon, L. F. da Silva, A. A. Cerqueira, P. B. Ximango and M. R. da Costa Marques, Journal of Water Process Engineering, 2015, 8, 126-135.

23 T. Janhom, S. Wattanachira and P. Pavasant, J. Environ. Manage., 2009, 90, 1184-1190.

24 M. Lin, X. Ning, T. An, J. Zhang, C. Chen, Y. Ke, Y. Wang, Y. Zhang, J. Su and J. Liu, J. Hazard. Mater., 2016, 307, 7-16.

25 J. Kochany and R. J. Maguire, Sci. Total Environ., 1994, 144, 17-31.

26 J. M. Ochando-Pulido, G. Hodaifa, M. D. Victor-Ortega, S. Rodriguez-Vives and A. Martinez-Ferez, J. Hazard. Mater., 2013, 263p, 158-167.

27 J. Wei, Y. Song, X. Tu, L. Zhao and E. Zhi, Chem. Eng. J., 2013, 218, 319-326.

28 P. Coble, Mar. Chem., 1996, 51, 325-346.

29 A. Baker and M. Curry, Water Res., 2004, 38, 2605-2613.

30 A. Baker, Environ. Sci. Technol., 2002, 36, 1377-1382.

31 S. Ciputra, A. Antony, R. Phillips, D. Richardson and G. Leslie, Chemosphere, 2010, 81, 86-91. 